\title{
A CRÍtica deleuZiana AO PRIMADO DA identidade em Aristóteles e em Platão
}

\author{
Sandro Kobol Fornazari
}

\begin{abstract}
RESUMO: seguindo a linha interpretativa de Deleuze, em Diferença e repetição, o artigo apresenta como, em Aristóteles e em Platão, a diferença é definida desde a primazia da identidade e como Deleuze rompe com ela, ao definir a diferença em si mesma. A filosofia da diferença deleuziana se compõe a partir da apreensão da diferença como virtualidade positiva e imanente, constituinte da univocidade do ser. No mesmo movimento, ela comporta uma crítica a toda filosofia que busca subordinar a diferença à representação, como em Aristóteles, em que a diferença está submetida à quádrupla raiz da identidade, da analogia, da oposição e da semelhança. Apesar disso, Deleuze explicita a noção de não-ser sem negação presente no Sofista de Platão como testemunho da potência da diferença em subverter a distinção modelo-cópia, ali onde havia um empenho em subordiná-la aos poderes da identidade e da semelhança.
\end{abstract}

PALAVRAS-CHAVE: Diferença. Ser unívoco. Identidade. Ideia. Simulacro.

A composição da filosofia da diferença em Gilles Deleuze, cujo ponto culminante é Diferença e repetição, comporta em si uma dupla e complementar elaboração, cujo propósito é a definição da diferença em si mesma. Por um lado, Deleuze realiza uma crítica à filosofia da representação, elencando de que modo, ao longo da História da Filosofia, a Identidade se instituiu como fundamento ontológico, relegando à diferença uma subordinação conceitual de maneira que, muitas vezes, foi confundida com a própria indeterminação ou indiferença ou mesmo declarada impensável em si mesma, por não cumprir as exigências do conceito. Essa crítica se dirige, ali, sobretudo a Hegel, Leibniz, Kant, Platão e Aristóteles. Por outro lado, Deleuze procura compor sua filosofia da diferença, liberando-a das amarras da tradição da filosofia da representação e visando

\footnotetext{
1 Sandro Kobol Fornazari é Professor Adjunto do Departamento de Filosofia da Escola de Filosofia, Letras e Ciências Humanas da Universidade Federal de São Paulo. Com defesa de tese sobre a filosofia de Gilles Deleuze, obteve o título de Doutor em Filosofia junto à Universidade de São Paulo, instituição na qual também realizou estágio de pós-doutoramento. É autor de Sobre o suposto autor da autobiografia de Nietzsche (Coleção Sendas \& Veredas; GEN/Discurso Editorial/editora UNIJUÍ, 2004).
} 
a apreender a diferença a partir de sua positividade constituinte do ser em sua univocidade, como potência imanente e subterrânea ao mundo das determinações empíricas sem que, com isso, deixasse de ser apreensível empiricamente, tratandose de renovar o empirismo e tornando-o transcendental. Nesse esforço criativo, encontra apoio sobretudo em Hume, Bergson, Nietzsche e Espinosa.

Este artigo enfoca dois momentos dessa crítica ao primado da Identidade: a subsunção da diferença à identidade do conceito de ser, em Aristóteles, em que ela é pensada com base na quádrupla raiz da identidade, da analogia, da oposição e da semelhança, e, na filosofia platônica, o modo como a diferença é repelida como falso pretendente diante da legítima pretensão da cópia em participar da Ideia como fundamento. Procura-se mostrar como o contraponto a essas filosofias e a recusa dos parâmetros da representação levam ao movimento criativo de definição do ser unívoco, a partir do conceito empírico-transcendental da diferença.

\section{A diferença indomável em Platão}

O inimigo freme, a diferença, insinuando-se por toda parte no cosmos platônico, resiste a seu jugo, Heráclito e os sofistas fazem uma algazarra dos infernos. (DELEUZE, 1988, p.211).

A dialética platônica procede diretamente sobre as coisas, sem a identidade de um conceito que sirva de mediação entre os termos que se procura dividir, sem um meio-termo que determine as diferenças como contrários de um mesmo gênero. Isso ocorre, segundo Deleuze, não por uma insuficiência do método, como a crítica que lhe dirigia Aristóteles, mas porque Platão não visa a determinar as espécies de um gênero comum, subsumindo as diferenças à identidade do conceito, mas pretende que o método de divisão da dialética seja, de fato, um método de seleção. E o que se trata de distinguir e de selecionar por tal método? A pretensão bem fundada das cópias em participarem da Ideia, eliminando os simulacros enquanto falsos pretendentes. Ao instituir um fundamento, por meio do qual julgar as pretensões dos rivais e estabelecer a diferença, a diferença será reportada ao Mesmo, cujo efeito é o de fazer com que a semelhança exista no fundado. Mais uma vez, ainda que de outro modo, a diferença aparece presa aos ditames da identidade, desta feita como Ideia. No platonismo, a diferença só pode ser pensada a partir da identidade originária e da cópia mais ou menos semelhante que dela deriva (DELEUZE, 1988, p.210). Daí a necessidade, na perspectiva de uma filosofia da diferença, de reverter o platonismo, no sentido de recusar o primado do original sobre a cópia e pensar a diferença em si mesma, sem a mediação de um modelo e sem subordiná-la ao Mesmo como fundamento. Para isso, os seres que se distinguem no sensível devem sofrer uma destruição 
radical de sua identidade, para que se descortine o fundo como realidade imediata (DELEUZE, 1988, p.121).

Desse modo, Deleuze reconhece, em Platão, a fundação do domínio da representação na filosofia, domínio preenchido pelas cópias-ícones numa relação intrínseca ao modelo. Fundar, neste caso, significa balizar, selecionar o que pertence a esse domínio e excluir dele o que pudesse baralhar seus limites, ou seja, trata-se de fazer a distinção entre as cópias e os simulacros.

O modelo ou fundamento é o que possui em primeiro lugar a qualidade do próprio fundamento, é o Mesmo como aquilo que é idêntico a si: a Justiça é justa, a Virtude é virtuosa, a Coragem é corajosa etc. A cópia é o que participa do fundamento, o que significa que ela possui em segundo lugar a qualidade de justa, virtuosa etc., ela é o Semelhante, cuja similitude exemplar e interna em relação ao modelo garante à cópia a justa pretensão em participar dele: os justos, os virtuosos, os corajosos etc. Por outro lado, existem as falsas pretensões, os pretendentes inautênticos que é preciso afastar, porque não possuem semelhança em relação ao modelo, são antes desvios e perversões que é preciso recalcar: os simulacros. As cópias são imagens semelhantes à Ideia, os simulacros são imagens sem semelhança. Nesse sentido, Deleuze aponta o objetivo do platonismo como o de selecionar o devir em função de uma ordenação ao Mesmo, tornando-o semelhante, impondo-lhe limites e, no mesmo movimento, recalcar o simulacro como aquilo que se esquiva à ordenação, ao limite, colocando em questão, com isso, as próprias noções de modelo e cópia.

A divisão é o método usado por Platão, seja para estabelecer a seleção do verdadeiro pretendente, aquele que é capaz de fazer com que a cópia se assemelhe ao modelo, seja para tratar de encurralar e capturar o falso pretendente como criador de ilusões e ficções verbais que escondem, sob sua superfície, os simulacros. No Sofista, a divisão é usada para encurralar o sofista como o falso pretendente e portador dos simulacros:

Eis, pois, o que ficou decidido: dividir sem demora a arte que produz imagens e, avançando nesse esconderijo, se, desde logo, nos aparecer o sofista, apanhá-lo conforme o edito do rei, entregando-o ao soberano, e declarando-lhe a nossa captura. E se, nas sucessivas partes da mimética, ele encontrar um covil onde se esconder, persegui-lo passo a passo, dividindo logo cada parte em que se resguarde, até que ele seja apanhado. Nem ele, nem espécie alguma, poderá jamais se vangloriar de se haver esquivado a uma perseguição levada a efeito tão metodicamente, em seu todo e em seus pormenores. (PLATÃO, Sofista, 235c-d).

Segundo Deleuze, Aristóteles vira nessa dialética da divisão um mau silogismo, porque a ela faltava a identidade de um conceito capaz de servir de 
mediação para a determinação das espécies: a qual das espécies opostas em que se dividiu um gênero pertence a coisa buscada? (DELEUZE, 1988, p.111-112). Contra o Filósofo, porém, argumenta que o objetivo da divisão platônica não é, a não ser ironicamente, a determinação de espécies a partir de um gênero. O objetivo da divisão não é a especificação, mas a seleção entre os rivais ou pretendentes em que se busca autenticar a linhagem pura, distinguir o bom pretendente dos maus, separar as cópias dos simulacros.

O mito seria um elemento integrante do método, na medida em que é a narrativa de uma fundação, erigindo um modelo a partir do qual os diferentes pretendentes poderão ser julgados de acordo com sua participação no modelo mítico. Deleuze exemplifica sua análise com o Político e o Fedro, diálogos nos quais a divisão é interrompida, antes que a seleção seja realizada, para dar lugar, respectivamente, ao mito dos tempos arcaicos e ao mito da circulação das almas. Neste último, as almas que puderam ver muito das Ideias antes de encarnarem têm muitas lembranças adormecidas que podem ser despertadas e a elas pertence o amor verdadeiro, enquanto os falsos pretendentes são as almas sensuais, que pouco viram e que pouco têm para rememorar. Em ambos, os pretendentes serão escolhidos com base em sua participação desigual no modelo mítico. $\mathrm{O}$ método seletivo é resolvido por uma participação eletiva segundo graus hierárquicos de participação. O fundamento ou a Ideia é o que tem a posse primeira de sua própria qualidade e que dá a participar ao pretendente, que tem a sua posse segunda, porque soube passar pela prova do fundamento e assim por diante, até aquele que não possui mais que um simulacro, uma imagem sem semelhança ou uma degradação da Ideia, e ele próprio não é mais que um simulacro, tal como o sofista e seus ensinamentos.

Para Deleuze, por conseguinte, o método da divisão define a motivação platônica, qual seja, selecionar, no domínio das imagens, as cópias como as pretendentes bem fundadas porque dotadas de semelhança, como as possuidoras em segundo lugar da qualidade que a Ideia dá a participar. "É a identidade superior da Ideia que funda a boa pretensão das cópias e funda-a sobre uma semelhança interna ou derivada" (DELEUZE, 1998, p.262). Ao mesmo tempo, a divisão recalca os simulacros como falsos pretendentes, sem participar do fundamento, porque estão submersos na dessemelhança.

Mas o que são, afinal, os simulacros, se eles não participam do ser nem em seu grau mais baixo, se não recebem dele uma semelhança, se nem ao menos passam pela Ideia? Deleuze afirma que há uma diferença de natureza entre a cópia e o simulacro, ou seja, este não pode ser na verdade uma cópia infinitamente degradada, uma semelhança afrouxada no mais alto grau. O que o simulacro faz é produzir um "efeito de semelhança" e, ao contrário das cópias, não é definido 
em relação à identidade do Mesmo. A imitação da cópia é noética, regulada em função da verdade da essência que ela reproduz. A imitação do simulacro é exterior à essência, designa um efeito de semelhança obtido ardilosamente, fazendo o dessemelhante passar pelo semelhante, o outro pelo mesmo, o grande pelo pequeno, o amor sensual pelo amor verdadeiro, o não-ser pelo ser, desfavorecendo o olhar dos espectadores, ao confundi-los, e sendo incapaz de chegar ao saber e à opinião correta.

O simulacro é construído sobre uma disparidade, sobre uma diferença, ele interioriza uma dissimilitude. [...] Se o simulacro tem ainda um modelo, trata-se de um outro modelo, um modelo do Outro do qual decorre uma dessemelhança interiorizada. (DELEUZE, 1998, p.263).

No Sofista, obra de velhice de Platão, a tentativa de definir o sofista como embusteiro, porque possuidor da arte do simulacro, obriga o autor a definir, antes, o que seja o próprio simulacro. Ora, se este é constituído exteriormente à essência e não participa dela em nenhum grau, é preciso admitir que o simulacro é outra coisa que aquilo que é (as Ideias). O Outro tem uma essência própria que, não somente é, como também se divide entre todos os seres desde que estejam em relações mútuas: "Há uma associação mútua dos seres. O ser e o outro penetram através de todos e se penetram mutuamente" (PLATÃO, Sofista, 259a-b), já que tudo que é o mesmo em relação a si é outro em relação a todas as coisas que não ele e tudo o que é outro em relação a um ser (algo que é) é. Assim, o devir é, na medida em que participa do ser; é o mesmo, já que participa do mesmo e é outro que não o ser; e, ainda, é outro que não o mesmo, porque participa do Outro. Portanto, há um ser do não-ser para todo e qualquer gênero que se considere. Nas palavras de Platão: "[...] pois a natureza do outro faz cada um deles outro que não o ser e, por isso mesmo, não-ser" (PLATÃO, Sofista, 256d). Por exemplo, o belo possui o não-belo como alteridade e não como contrariedade, ou seja, o não-belo não é apenas o feio, podendo ser também o comum, o repugnante, o disforme etc.

Em suma, a negação que acompanha a alteridade significa "alguma coisa de diferente" (Platão, Sofista, 257b-258b) em relação ao gênero que se nega, em virtude do modelo do Outro, e o próprio não-ser não significa algo contrário ao ser, mas outra coisa que não o ser e, por participar do ser, é preciso reconhecer que o não-ser é ser. "Assim, cada forma encerra uma multiplicidade de ser e uma quantidade infinita de não-ser" (Platão, Sofista, 256e). O não-ser não é o contrário do ser e, por isso, não é menos ser que o próprio ser, o não-ser é o que difere do ser entendido como fundamento. E, ainda mais, o não-ser tem uma natureza própria, o que significa que existe, também, enquanto modelo ou fundamento. 
Ao comentar essa noção da alteridade como aquilo que difere do ser, Gérard Lebrun considera que, nos marcos da metafísica clássica, a negação só pode ser tomada como uma “[...] abertura dum campo indeterminado" (LEBRUN, 1972, p.178-180). Nesse sentido, ao afirmar que algo difere de tudo aquilo que ele não é, essa negação designa a soma indeterminada de todas as outras coisas. Com isso, o negativo parece ter como função pôr em relevo o conteúdo positivo que o pensamento procura apreender, separando-o de todos os outros como de seu limite. Assim, estaria assegurada a indestrutibilidade intrínseca da cada determinação. Contra essa doutrina clássica da negação como alteridade, Lebrun defende a tarefa da filosofia hegeliana de pensar a relação entre uma coisa e seu outro como uma relação determinante, quer dizer, que reenvia a uma negação que não é indiferente àquilo que nega, mas que o menciona necessariamente. Desse modo, os dois estão numa relação essencial, isto é, um existe na medida em que exclui o outro de si, tal como o inorgânico não é simplesmente alguma coisa de outro em relação ao orgânico, mas sim o seu outro necessário: o inorgânico não é sem o orgânico e vice-versa.

Ora, Deleuze se afasta de ambas soluções, quando afirma que há o nãoser, mas que o negativo é ilusório, porque o "não" de "não-ser" exprime algo distinto de uma negação, seja por limitação, seja por oposição:

O erro das teorias tradicionais é impor-nos uma alternativa duvidosa: [...] ou bem não há não-ser, e a negação é ilusória e não fundada; ou bem há nãoser, que põe o negativo no ser e funda a negação. Todavia, talvez tenhamos razões para dizer, ao mesmo tempo, que há não-ser e que o negativo é ilusório. (DELEUZE, 1988, p.117).

Porque o "não" de "não-ser" exprime o devir louco que se insinua por toda parte e em profundidade, o não-ser é a diferença. Sobre ela se constitui o simulacro, que não se subsume à identidade do modelo. Mais que isso, as próprias noções de modelo e de cópia são contestadas e reenviam ao próprio funcionamento do simulacro e ao jogo mais profundo das diferenças que produz todo um sistema de semelhanças e identidades, elas mesmas não passando de simulacros (DELEUZE, 1988, p.209 e 213). E, por mais que Platão saia no encalço da diferença e no encalço do sofista como um tipo de porta-voz da diferença ou produtor de simulacros, ela insiste, e apresenta-se com força e decisão, a partir das zonas não iluminadas pelas Ideias, na obscuridade do não-ser, indomada.

Por conseguinte, uma das grandes contribuições desse diálogo deleuziano com Platão é mostrar que somente é possível pensar a diferença em si mesma com a condição da destruição radical da identidade dos seres sensíveis, que se distinguem no diferente, e de sua pretensão em possuir uma semelhança em 
relação a um fundamento. Sem isso, a diferença permaneceria aprisionada sob uma falsa pretensão do simulacro e subordinada à primazia do modelo e da cópia.

Todo platonismo está construído sobre esta vontade de explicar os fantasmas ou simulacros [...]. Com Platão, estava tomada uma decisão filosófica da maior importância: a de subordinar a diferença às potências do Mesmo e do Semelhante, supostamente iniciais, a de declarar a diferença impensável em si mesma e de remetê-la, juntamente com os simulacros, ao oceano sem fundo. (DELEUZE, 1988, p.211).

Eis o verdadeiro sentido da reversão do platonismo: a glorificação do reino dos simulacros, subvertendo a distinção modelo-cópia, essência-aparência, descerrando a potência positiva da diferença. No platonismo revertido, a semelhança e o mesmo não são mais que efeitos exteriores do simulacro. Ao dissolver-se a identidade e a semelhança das coisas, o ser deixa de fazer sentido enquanto fundamento, desaparece enquanto fundamento e, assim, "[...] atinge a univocidade e se põe a girar em torno do diferente" (DELEUZE, 1988, p.121).

\section{Os LIMITES À DIFERENÇA EM ARIstóteles}

Para Deleuze, diferentemente de Platão, Aristóteles representa o feliz momento grego, momento em que a diferença seria reconciliada com as exigências da representação, o que teria afastado, no entanto, a filosofia aristotélica de ser capaz de estabelecer um conceito singular da diferença (DELEUZE, 1988, p.65). Seguindo nessa trilha, começamos por tentar compreender de que se trata, nesse momento feliz.

Nesse feliz momento, primeiramente, a diferença deve passar por uma prova seletiva para determinar qual a grandeza ou a pequenez que deve ter a diferença, para entrar nos limites do conceito. O Filósofo outorga à diferença uma natureza predicativa em relação à identidade de um conceito indeterminado (o gênero), isto é, a diferença específica é inscrita no gênero, dividindo-o em espécies que apresentam entre si uma contrariedade. Nesse sentido, um gênero sem diferença é impossível, porque é a diferença que, ao acrescentar-se ao gênero, forma sempre uma espécie (ARISTÓTELES, Tópicos, VI, 6). Por exemplo, o gênero animal se divide em "dotado de pés" e "dotado de asas". A contrariedade entre as espécies não deriva das diferenças entre os seres concretos ou a matéria, por exemplo, não há diferença em espécie entre um círculo de bronze e um círculo de madeira, contudo, um triângulo de bronze difere em espécie de um círculo de madeira, não por causa de sua matéria, mas sim por haver contrariedade nas definições de triângulo e de círculo (ARISTÓTELES, Metafisica, X, 9). A diferença específica, desse modo, é aquela que cria uma contrariedade na definição 
das espécies pertencentes a um gênero que permanece o mesmo para ambas; ela responde, além disso, ao critério da seleção para a diferença ser inscrita no conceito em geral. A fim de que a diferença entre dois termos seja essencial, é preciso que eles cumpram o duplo critério: a) que convenham também numa outra coisa que permaneça a mesma e b) que possuam uma contrariedade. $\mathrm{Na}$ matéria, a diferença entre indivíduos perde-se aquém do conceito, porque suas diferenças empíricas são sempre acidentais e extrínsecas (o bronze e a madeira, por exemplo), não havendo contrariedade entre elas. No gênero, por sua vez, a diferença escapa além do conceito geral, na medida em que também os gêneros não entram em relação de contrariedade.

O gênero é esse algo idêntico, essa natureza comum que há entre duas coisas, como, por exemplo, entre dois animais. O cavalo e o homem são ambos de uma natureza comum, mas entre eles há uma diferença específica, quer dizer, a própria animalidade é diferente para cada um: a natureza equina e a natureza humana. Portanto, toda diferença de espécie é uma diferença entre duas coisas contrárias no interior de uma terceira, que é a mesma para ambas e constitui o seu gênero. Os contrários que diferem em espécie estão na mesma linha de predicação e diferem entre si no mais alto grau, caracterizando a completude ou a perfeição da diferença.

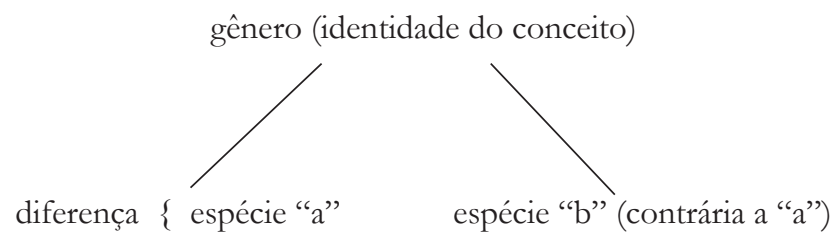

Deleuze vê nessa operação de Aristóteles, que inscreve a diferença no conceito indeterminado de gênero, a "confusão fundamental" da qual se deriva a subordinação da diferença à oposição, à analogia, à semelhança e à identidade. Porém, Deleuze vê também a introdução de uma "rachadura" no pensamento, que não cessará de crescer numa atmosfera não aristotélica. Vejamos em que consistem essa confusão e essa abertura em que Aristóteles teria envolvido a diferença.

A diferença específica ou a contrariedade entre espécies é a maior das diferenças, a diferença perfeita. No entanto, ela só existe enquanto referida e sob a condição da identidade do conceito de gênero. Inversamente, entre as coisas que diferem em gênero há uma distância tão grande que não é possível sequer compará-las (ARISTÓTELES, Metafísica, X, 4). Ao contrário das espécies em relação ao gênero, e este é o segundo passo dado por Aristóteles ao lidar com a diferença, os gêneros, enquanto considerados como os últimos conceitos 
determináveis (as categorias), não estão submetidos à condição de ter um conceito idêntico que os subsume, isto é, uma natureza comum, tal como o um ou o ser, que fosse compartilhada por dois gêneros distintos. Os gêneros vão mover-se na equivocidade do ser, e de nenhuma maneira vão relacionar-se com ele como as espécies o fazem quanto a um gênero único. Enquanto as espécies são unívocas em relação ao gênero, o gênero é equívoco em relação ao ser.

A razão para isso é que nem o ser, nem o um podem ser gêneros. Assim Aristóteles argumenta:

\begin{abstract}
Mas não é possível que o um e tampouco o ser seja um gênero único das coisas; pois necessariamente existem as diferenças em cada gênero, e cada uma dessas diferenças não só é como também é uma; mas o gênero considerado à parte de suas espécies (assim como a espécie considerada à parte do gênero) não pode ser predicado de suas diferenças peculiares; logo, se o um ou o ser é um gênero, nenhuma diferença possuirá "ser" ou será uma. (ARISTÓTELES, Metafisica, III, 3, 998b 20-30).
\end{abstract}

Ao referir-se a essa passagem da Metafísica, Deleuze ressalta que o motivo pelo qual, em Aristóteles, o ser não é um gênero é porque as diferenças são (e poderia acrescentar: cada uma delas é uma). Ora, na medida em que tudo é ser, não é possível negar existência às diferenças específicas e, assim, se o ser fosse um gênero, ele seria atribuído às diferenças, o que é impossível. Por que é impossível? Porque, se fosse possível ao gênero predicar as diferenças, então, por exemplo, o gênero animal seria dito da espécie humana e também da diferença que constitui a espécie humana enquanto racional e as demais espécies como não-racionais. $\mathrm{E}$ dessa possibilidade seguiriam duas consequências: primeiro, se "animal" tivesse de predicar-se de suas diferenças, sendo as diferenças predicados de suas espécies, então "animal" se predicaria das espécies, uma vez no que concerne ao gênero e uma através da diferença, em cada linha de predicação; e, em segundo lugar, de cada uma das diferenças se constituiria uma espécie além daquelas que ela já constitui, no caso, a espécie da diferença racional (ARISTÓTELES, Tópicos, VI, 6). ${ }^{2}$

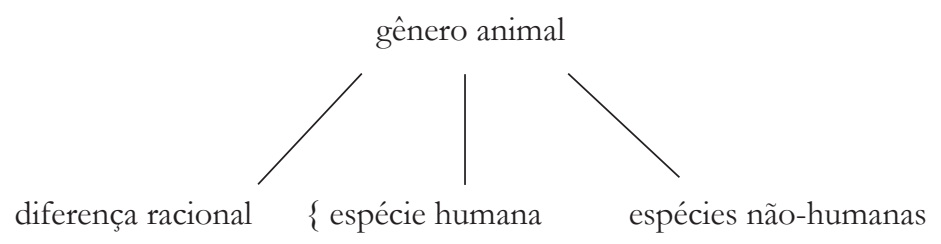

${ }^{2}$ Ver análise de Pierre Aubenque (1983, p.229-233). 
Mas, se assim fosse, isto é, se o gênero pudesse ser predicado da diferença, a diferença não seria o princípio de especificação. Se a racionalidade fosse animal, por que definir o homem como animal racional, se a própria racionalidade já implicaria a animalidade? Como distinguir o homem da própria racionalidade e como definir o homem em sua espécie como o único animal racional, se toda racionalidade é animal?

Desse modo, se o gênero pudesse ser atribuído às diferenças específicas, se a diferença fosse uma espécie do gênero, ela não seria capaz de atuar como princípio de especificação. Nesse sentido, é preciso que a diferença seja em si mesma e não um produto da divisão do gênero. Ela constitui uma espécie em contrariedade com outra e, exatamente por isso, não pode ser uma espécie; se o fosse, confundir-se-ia com a espécie que diferencia. Portanto, a diferença é necessariamente estranha ao gênero.

Logo, se o ser fosse um gênero, comportaria diferenças que constituiriam as espécies e, na medida em que essas diferenças são seres, o ser como gênero seria predicado de suas diferenças, o que é impossível, porque as diferenças são necessariamente estranhas ao gênero, sem o que não seriam capazes de constituir as espécies.

Vale frisar que, quando dizemos que a diferença é em si mesma, não devemos entender com isso que a diferença tenha uma extensão própria, pois a diferença, em Aristóteles, somente tem sentido em relação ao gênero que ela vem especificar, por exemplo, a diferença que constitui as espécies racional e irracional faz sentido apenas em referência ao gênero animal, não existindo fora desse domínio. ${ }^{3}$

De acordo com Deleuze, consequentemente, existem na filosofia de Aristóteles duas definições distintas, mas complementares de diferença, que assinalam seus limites, conforme nos referimos às espécies ou aos gêneros últimos ou categorias:

1. Diferenças específicas: a diferença entre as espécies inscreve a diferença na identidade do conceito indeterminado de gênero, ou seja, duas espécies diferem entre si sob algum aspecto, permanecendo, entre elas, algo de idêntico como predicado de ambas, que nada mais é que o gênero do qual ambas as coisas se especificaram. Em decorrência, os contrários são idênticos em gênero, mas são outros em espécie (ARISTÓTELES, Metafísica, X, 3). Não

\footnotetext{
3 Aubenque argumenta, em acréscimo, que a diferença não pode ser exercida senão em referência a um domínio determinado; no caso do ser, em que o domínio é infinito, a diferença não pode efetivarse por carecer de um "ponto de apoio". Também nesse sentido se prova que, porque não pode comportar diferenças, o ser não é um gênero (AUBENQUE, 1983, p.231). 
bá, aqui, propriamente, o estabelecimento de um conceito da diferença, mas sim a inscrição da diferença enquanto predicado na identidade de um conceito. A diferença, embora seja o princípio da especificação do gênero, não tem mais que um papel mediador e conciliador entre o mais universal, o gênero, e o mais singular, o indivisível, nos níveis sucessivos de divisão da espécie. O que Deleuze reprova em Aristóteles é ele não ter apresentado "[...] um conceito universal para todas as singularidades e sinuosidades da diferença" (DELEUZE, 1988, p.69), subordinando, assim, a diferença à identidade.

2. Diferenças genéricas: subsiste, na diferença categorial, um conceito idêntico, embora de modo especial, qual seja, o conceito de ser enquanto distributivo e hierárquico. Distributivo, porque o conceito de ser não tem conteúdo em si, mas sim um conteúdo proporcionado às categorias das quais é predicado e que são formalmente diferentes entre si; a relação das categorias com o ser é interior a cada uma, ou seja, é por sua natureza própria que cada categoria tem unidade e ser. Assim, existe uma equivocidade do ser em relação às categorias, quer dizer, o ser se diz em vários sentidos, a partir das diferentes categorias. Contudo, cada sentido do ser é sempre relativo a um princípio único: a ousía (substância) e, por isso, o conceito de ser é hierárquico. Não se trata, portanto, de uma relação entre um gênero e espécies unívocas, porque o conceito de ser tem um sentido hierarquicamente primeiro (ele é princípio e fundamento) e um sentido comum apenas distributivo, como podemos conferir numa das célebres passagens da Metafísica:

[...] são vários os sentidos em que dizemos que uma coisa "é", mas todos
eles se referem a um só ponto de partida: algumas coisas "são" pelo fato de
serem substâncias, outras por serem modificações da substância, outras por
representarem um trânsito para ela, a destruição, a privação ou uma qualidade
dela, ou pelo fato de a produzirem ou gerarem, ou por serem termos relativos
à substância, ou negações de um desses termos ou da própria substância. [...]
[A substância é] o que é primário, do qual dependem as outras coisas e do qual
recebem sua denominação. (ARISTÓTELES, Metafísica, IV, 2, 1003b 5-20).

A diferença é, por conseguinte, mediação entre as duas faces do conceito de ser, isto é, ela se passa no ser "entre" a substância, como sentido primeiro, e os acidentes da substância, que são as categorias e que se dizem em função do ser (DELEUZE, 1998, p.7-8).

Não sendo um gênero para as categorias e possuindo um conceito distributivo e hierárquico, o ser equívoco é, na verdade, uma analogia do juízo. O juízo seria "[...] a instância capaz de proporcionar o conceito aos termos ou aos sujeitos dos quais é ele afirmado" (DELEUZE, 1988, p.72), porque uma das faculdades do juízo é o senso comum, através do qual ele partilha o conceito, 
assegurando a distribuição; a outra faculdade é o bom senso, ou sentido primeiro, pelo qual o juízo mede os sujeitos, assegurando a hierarquização. O juízo é tomado como modelo para as duas formas em que o ser se relaciona com as categorias: distributivamente e como precedência hierárquica. Nesse sentido, a analogia do juízo na representação é o que permite afirmar, a partir da equivocidade do ser, a quase-identidade do conceito nas categorias.

Eis por que não podemos esperar que a diferença genérica ou categorial,
não mais que a diferença específica, nos comunique um conceito próprio
da diferença. Enquanto a diferença específica se contenta em inscrever
a diferença na identidade do conceito indeterminado em geral, a diferença
genérica (distributiva e hierárquica) se contenta, por sua vez, em inscrever a
diferença na quase-identidade dos conceitos determináveis mais gerais, isto
é, na própria analogia do juízo. Toda a filosofia aristotélica da diferença está
contida nesta dupla inscrição complementar, fundada num mesmo postulado,
traçando os limites arbitrários do feliz momento. (DELEUZE, 1988, p.72-73).

Dessa forma, Deleuze mostra que a diferença, em Aristóteles, aparece, num caso como no outro, como um conceito reflexivo: através da diferença, podese passar, numa percepção direta, das espécies semelhantes à identidade de um gênero que as subsume, além de compreender os gêneros idênticos superiores, as categorias, como os vários sentidos em que o ser se diz. Ora, como vimos, é o fato de que as diferenças específicas sejam que impossibilita que as diferenças entre as categorias se relacionem com o ser, como se ele fosse um gênero comum e, assim, "[...] a univocidade das espécies num gênero comum remete à equivocidade do ser nos gêneros diversos: uma reflete a outra" (DELEUZE, 1988, p.73). Logo, se se pode dizer que cada categoria, por sua própria natureza, tem unidade e ser, isso se deve a uma analogia operada pelo juízo na representação, que compreende o ser como distributivo e hierarquicamente anterior (fundamento). Portanto, como conceito reflexivo, a diferença se encontra plenamente submetida às exigências da representação, definida nesse caso, por Deleuze, como representação orgânica. A representação orgânica fixa os limites para a diferença com base nas formas concretas ou das determinações das espécies e dos gêneros, submetidas às exigências do conceito em geral. Consequentemente, pode-se censurar Aristóteles, ao fixar os limites para a inscrição da diferença na identidade do conceito, por ter perdido o sentido comum do ser, que só se distribui nas categorias para dar a cada uma sua parte, assim como por não dar conta da singularidade, na medida em que o indivíduo singular só possui diferenças em geral, quer dizer, que compartilha com os demais indivíduos da mesma espécie (DELEUZE, 1988, p.474).

Tal operação de concordância da diferença com todas as exigências da representação depende do juízo reflexivo, que mediatiza a diferença, ao subordiná- 
la à identidade do conceito de gênero e ao garantir essa subordinação no conceito quase-idêntico ou análogo de categoria, na oposição lógica das determinações e na semelhança dos conteúdos materiais.

Com isso, temos em Aristóteles a realização do feliz momento em que a diferença está quase totalmente domada, ao submeter-se à quádrupla raiz da identidade (do conceito indeterminado de gênero), da analogia (do juízo na relação entre conceitos determináveis ou categorias), da oposição (dos predicados na relação das determinações ou espécies) e da semelhança (da percepção no objeto determinado ou indivíduo.$^{4}$

\section{O NOMAdISMo E A ANARQUiA DA DIFERENÇA EM DELEUZE}

"A diferença em si mesma", primeiro capítulo de Diferença e repetição, inicia apontando para uma definição positiva da diferença como "[...] algo que se distingue - e, todavia, aquilo de que ele se distingue não se distingue dele" (DELEUZE, 1988, p.63). O exemplo dado é o do relâmpago em relação ao céu negro. O relâmpago dele se distingue, luta para opor-se a ele, mas não é possível ao céu negro dele se distinguir. Assim, o relâmpago é uma distinção unilateral, distinto e indistinguível do céu carregado que o engendra, como um fundo que sobe à superfície, mas que não deixa de ser fundo. A diferença não pode ser entendida como diferença empírica entre duas coisas. No mundo das determinações, não há propriamente diferenças, suas diferentes características são meramente extrínsecas e as determinações são indiferentes umas com respeito às outras. Tampouco o abismo da indeterminação em que tudo é dissolvido comportaria diferenças: seria indiferença completa. Onde apreendemos, então, a diferença, se não nesse movimento em que o fundo sobe à superfície sem deixar de ser fundo? A diferença se estabelece como distinção unilateral desse fundo, que se destaca do fundo indeterminado (que permanece lá) e adquire uma existência autônoma.

O principal corolário da diferença é o conceito de univocidade do ser. A diferença é o que inicialmente difere de si mesmo, o movimento em que um fundo sobe à superfície sem deixar de ser fundo. O ser unívoco é justamente esse fundo de que se destacam todas as diferenças individuantes sem que deixem de, em sua diferença, reportar-se ao único sentido em que esse ser se diz: “[...] o Ser

4 Quase domada porque, segundo Deleuze, a diferença ainda reencontra um conceito fora da representação, quando ela designa "catástrofes", ou seja, rupturas de continuidade na série de semelhanças, falhas intransponíveis entre estruturas análogas, dando "[...] testemunho de um fundo rebelde irredutível que continua agindo sob o equilíbrio aparente da representação orgânica." (DELEUZE, 1988, p.74). Infelizmente, Deleuze é apenas alusivo em relação a esse fundo rebelde na filosofia de Aristóteles, em que a diferença designa descontinuidades e quebras em relação à quádrupla raiz. 
se diz num único sentido de tudo aquilo de que ele se diz, mas aquilo de que ele se diz difere: ele se diz da própria diferença" (DELEUZE, 1988, p.76).

Mais que afirmar que o ser se diz num único sentido, a univocidade significa que o ser se diz num único sentido de todas as suas diferenças individuantes. Seguindo o modelo da proposição, o ser é o designado comum que permanece o mesmo em relação aos designantes, mas também o sentido dos modos individuantes ou dos designantes numericamente distintos é ontologicamente o mesmo, não obstante podermos conceber sentidos formal ou qualitativamente distintos para esses modos. Às diferenças individuantes nos modos corresponde a unidade do sentido do ser, como o branco que permanece essencialmente branco, apesar das diversas intensidades de branco às quais ele pode reportar-se, como os próprios graus da luz branca constituem cada cor em sua singularidade. A própria multiplicidade das diferenças é o designado comum para o virtual e para a univocidade. Assim, dizer que há uma só voz do Ser, “[...] uma só voz faz o clamor do ser" (DELEUZE, 1988, p.75), não permite negligenciar que ele se diz de todos os seus modos, de todas as suas variações ou, numa só palavra, da própria diferença. O ser unívoco se diz imediatamente da diferença e, nesse sentido, o ser é diferença e nós, enquanto individualidade, permanecemos equívocos para um ser unívoco.

Por isso, Deleuze pode contrapor-se criticamente à ontologia aristotélica, já que teria fracassado em sua tentativa de chegar a uma definição da diferença, na medida em que a manteve submissa, enquanto diferença genérica e específica, às exigências da representação.

Em primeiro lugar, porque no ser unívoco há uma hierarquia e uma distribuição das diferenças individuantes totalmente inconciliável com aquela que é pressuposta pelo ser equívoco, em sua relação analógica com as categorias em Aristóteles. Vimos que, de acordo com o Filósofo, há uma repartição do ser enquanto distribuído, implicando a fixidez e a proporcionalidade do que se distribui em "propriedades" limitadas na representação. Deleuze, ao contrário, reclama uma distribuição nomádica, em que o que se distribui o faz num espaço aberto, sem propriedade, sem limites precisos, quando não, ilimitado, disposto aqui e ali, cobrindo o maior espaço possível. Não se trata de partilhar um território, como o ser se partilha segundo as exigências da representação, mas de partilharse nele, de modo que as coisas se desdobram no extenso do ser unívoco, "[...] na univocidade da simples-presença, [...] como saltando por cima das barreiras ou das cercas, queimando as propriedades" (DELEUZE, 1988, p.77). Também quanto à hierarquia, há uma nova concepção que, ao invés de medir os seres segundo seus limites e a partir de sua proximidade ou distanciamento em relação a um princípio ou fundamento, considera as coisas do ponto de vista da potência, não em termos de graus absolutos de potência, mas em termos de capacidade de 
um ser ir ao extremo daquilo que pode, ultrapassar seu limite próprio, realizar seu "salto". Pode-se ainda supor um limite, não como uma limitação, mas um ponto a partir do qual o ser se desenvolve e desenvolve sua potência. Como esse limite é relativo ao grau de potência próprio a cada ser, segue-se que ele é a mesma medida para todas as coisas, é o máximo próprio para cada ser. Assim, todas as coisas participam igualmente do ser, que está presente em todas elas imediatamente, sem mediação. Essa hierarquia está na verdade mais próxima de uma anarquia dos seres do que de um princípio hierárquico. Nenhuma coisa, grande ou pequena, participa mais ou menos do ser, nenhuma o recebe por analogia, o menor tornase igual ao maior uma vez que não está separado daquilo que pode. A univocidade significa também a igualdade do ser, que é, ao mesmo tempo, na bela formulação de Deleuze, "distribuição nômade e anarquia coroada".

Em segundo lugar, porque a diferença específica, em Aristóteles, não pode dar conta de explicar o que constitui a singularidade de um existente, porque visa ao princípio de individuação pelos elementos já constituídos, retendo no indivíduo apenas o que é conforme ao geral, isto é, sua forma. O ser unívoco, por outro lado, se diz das próprias diferenças individuantes e está presente sem mediação em cada uma delas. Se, em Aristóteles, o ser não é um gênero, porque as diferenças específicas são, o ser unívoco, ao contrário, é comum justamente porque as diferenças individuantes "não são", pois essas diferenças, está claro, não são entendidas como indivíduos constituídos na diversidade da experiência, mas sim como o princípio transcendental que age nesses indivíduos:

[...] princípio plástico, anárquico e nômade, contemporâneo do processo de individuação, e que não é menos capaz de dissolver e destruir os indivíduos quanto de constituí-los temporariamente: modalidades intrínsecas do ser, passando de um "indivíduo" a outro, circulando e comunicando sob as formas e as matérias. (DELEUZE, 1988, p.79-80).

A diferença individuante, que se desdobra no ser unívoco, precede todo e qualquer elemento do indivíduo constituído, como a forma e a matéria, mas também as diferenças genéricas, específicas e entre indivíduos, porque é como um campo condicionante de toda especificação das formas, de toda determinação e de todas as variações individuais. O que é necessário para uma filosofia da diferença é mostrar como se dá essa precedência e de que maneira se dá esse condicionamento das formas, das matérias e das partes extensivas em relação à diferenciação (ou individuação).

Está definida, portanto, a tarefa da filosofia da diferença, que se confunde com a reversão do platonismo: pensar a diferença em si mesma, e talhar um conceito singular da diferença que não se confunda com uma diferença conceitual, 
o que implica elaborar uma ideia de diferença que não esteja subordinada à representação, isto é, que ela seja liberada da coerência e da identidade do conceito em geral: de um sujeito que se representa $(\mathrm{Eu}=\mathrm{Eu})$ e do conceito de um objeto representado (A é A). O movimento abstrato de convergência para a identidade cede diante do jogo, mais profundo, de remissões recíprocas entre diferenças que nunca se identificam, mas que se diferenciam em séries desprovidas de centro. "É preciso afirmar a divergência e o descentramento na própria série. Cada coisa, cada ser deve ver sua própria identidade tragada pela diferença, cada qual sendo só uma diferença entre as diferenças. É preciso mostrar a diferença diferindo" (DELEUZE, 1988, p.107).

Assim se desdobrará a filosofia deleuziana até a conclusão de Diferença e repetição, flertando com as forças que agem sob a representação. Uma tese que permeia o livro é de que a diferença nunca deixa de insinuar-se mesmo ali onde um filósofo a submete às amarras de um conceito geral ou encontra um método que faz com que ela seja repelida em sua falsa pretensão em participar do fundamento. Porém, a filosofia da diferença recusa mediações e representantes e a negatividade não passa de um efeito de superfície, porque o ser, afirmação pura e subterrânea, se diz num único sentido de tudo aquilo de que se diz, o ser se diz da diferença. A filosofia da diferença se define, portanto, como um empirismo superior ou transcendental, que busca sob o sensível a razão do sensível, qual seja, a diferença (de potencial, de intensidade). Apenas como efeitos de superfície existem a semelhança, a analogia, a oposição e a identidade, porque a diferença é uma multiplicidade e um caos, com suas distribuições nômades e sua anarquia coroada.

FORNAZARI, S. K. The Deleuzian critique to the primacy of identity on Aristotle and Plato. Trans/Form/Ação, Marília, v. 34, n.2, p. 3-20, 2011.

ABSTRACT: Following the interpretative line of Deleuze in Difference and Repetition, the paper shows how, in Aristotle and Plato, the difference is defined from the primacy of identity and how Deleuze breaks it to define the difference itself. The Deleuzian philosophy of difference is composed from an apprehension of difference as positive and immanent virtuality constituent of univocal being. In the same motion, it includes a critique of philosophy that seeks to make the difference subject to the representation, as in Aristotle, in which the difference is subject to the fourfold root of identity, analogy, similarity and opposition. Nevertheless, Deleuze explains the concept of nonbeing without negation from Plato's Sophist as testimony of the power of the difference in subverting the distinction copy-model, where there was a commitment to subordinate it to the powers of identity and similarity.

KEYWORDS: Difference. Univocal being. Identity. Ideas. Simulacrum. 
A crítica deleuziana

\section{REFERÊNCIAS}

ARISTÓTELES. Metafísica. Tr. Leonel Vallandro. Porto Alegre: Globo, 1969.

Tópicos. Aristóteles. V. I. 4. ed. Tr. Leonel Vallandro; Gerd Bornheim. São Paulo: Nova Cultural, 1991 (Os pensadores).

AUBENQUE, Pierre. Le problème de l'être chę Aristote. 5. ed. Paris: PUF, 1983.

DELEUZE, Gilles. Diferença e repetição. Tr. Luiz Orlandi; Roberto Machado. Rio de Janeiro: Graal, 1988.

Lógica do sentido. 4. ed. Tr. Luiz R. Salinas Fortes. São Paulo: Perspectiva, 1998.

FORNAZARI, Sandro K. O esplendor do ser: a composição da filosofia da diferença em Gilles Deleuze (1952-1968), 2005. 174 f. Tese (Doutorado em Filosofia) - Faculdade de Filosofia, Letras e Ciências Humanas, Universidade de São Paulo, São Paulo, 2005.

LEBRUN, Gérard. La patience du concept. Essai sur le Discours hégélien. Paris: Gallimard, 1972.

PLATÃO. Sofista. Tr. Jorge Paleikat: João Cruz Costa. Diálogos. 5. ed. São Paulo: Nova Cultural, 1991 (Os pensadores).

Recebido em: 4 de abril de 2011

Aprovado em: 7 de maio de 2011

Trans/Form/Ação, Marilia, v. 34, n. 2, p. 3-20, 2011 